\title{
As mídias virtuais no Brasil (2014-2018): condições de produção da docência
}

\author{
The virtual media in Brazil (2014-2018): the conditions of teaching production \\ Marcos Salmo Silva de LIMA* \\ Universidade Federal do Rio Grande do Sul (UFRGS)
}

RESUMO: Neste estudo, que deriva de pesquisa realizada durante o curso de mestrado em educação (PPGEDU/UFRGS), entre 2015 e 2017, fizemos um levantamento de artigos da internet, que circularam entre 2014 e 2018, relacionados aos contextos vividos pelos profissionais da educação com o objetivo de apresentar um panorama das condições de produção do ser/estar docente no contexto brasileiro, tanto discorrendo sobre a educação e a formação docente quanto desenhando um trajeto que inclui problematização sobre sua (des)valorização, sua identidade, seu papel e função social. O problema que inquieta envolve compreender como as condições de produção do magistério no Brasil afetam esta prática social que é a docência. Para um tal empreendimento, mobilizamos o conceito de condições de produção da Análise de Discurso francesa, que tem Michel Pêcheux como seu fundador, mas sem a intenção de produção de uma análise de discurso em si haja vista este trabalho ser de caráter mais teórico e de contextualização. Para suporte a respeito da temática da formação, identidade e valorização docente, os autores Claude Lessard, Maurice Tardif, Antônio Nóvoa e Dóris Fiss foram importantes.

PAlavRAS CHAVES: Condições de Produção. Trabalho docente. Análise de Discurso. Educação.

\begin{abstract}
In this study, derived from research conducted during the master's degree course in education (PPGEDU / UFRGS), between 2015 and 2017, we did a survey of internet articles, which circulated between 2014 and 2018, related to the contexts experienced by education professionals with the objective of presenting a panorama of the conditions of production of being / teaching in the Brazilian context, both discussing education and teacher education and designing a path that

\footnotetext{
* Doutorando em Educação pelo Programa de Pós-Graduação em Educação da Universidade Federal do Rio Grande do Sul, Linha de Pesquisa Arte, Linguagem e Currículo, Eixo Temático: Docência e Discurso. Professor de Língua Portuguesa da rede municipal de Canoas - RS. E-mail: salmo.socram.ms@gmail.com.
} 
includes problematization about its (dis) valorization, identity, role and social function . The disturbing problem involves understanding how the conditions of production of teaching in Brazil affect this social practice that is teaching. For such an undertaking, we mobilize the concept of conditions of production of the French Discourse Analysis, which has Michel Pêcheux as its founder, but without the intention of producing a discourse analysis in itself since this work is of a more theoretical and contextualization. To support the theme of teacher training, identity and appreciation, authors Claude Lessard, Maurice Tardif, Antônio Nóvoa and Dóris Fiss were important.

KEYWORDS: Production condition. Teacher working. Speech analysis. Education.

\section{Introdução}

Nas últimas décadas, o "fracasso" dos alunos e a debilidade do sistema escolar público têm indicado o docente como o grande responsável. A valorização social, econômico-financeira e profissional no âmbito da docência pública e privada está bastante defasada, acarretando no desinteresse pelos cursos de licenciatura em todo território nacional. Está ocorrendo uma espécie de "apagão docente” segundo Vera Maria Candau De acordo com estudos de Fiss (1998; 2003), em trabalho que discorre sobre o mal-estar docente manifesto em depoimentos analisados no período entre 1996 e 2003, há uma presença de sentidos de crise do magistério e da profissão docente que, por vezes, são associados, pelo professores interlocutores da investigação realizada, às condições de produção adversas da docência das quais decorre sofrimento físico e psicológico com risco de degeneração do trabalho e do investimento no mesmo.

A esse respeito, consideramos discursos vinculados, entre os anos de 2014 a 2018 , pela mídia virtual sobre vivências, trabalhos excessivos e saúde debilitada dos professores, atentando para as seguintes notícias publicadas: "Professor sofre com estresse, violência e falta de tempo para planejar aula", "Quase 90\% dos professores brasileiros se sentem

\footnotetext{
1 Termo utilizado por Vera Maria Candau em palestra proferida no último Encontro Nacional de Didática e Práticas de Ensino ocorrido na Universidade Federal do Ceará em 2018.

2 Disponível em: http://educacao.uol.com.br/noticias/2015/10/15/professor-sofre-com-estresse-violencia-efalta-de-tempo-para-planejar-aula.htm. Acesso em dezembro de 2018.
} 
desvalorizados, diz estudo", "Professor brasileiro gasta $20 \%$ do tempo de aula com indisciplina", "Em média, professor no Brasil tem jornada de 25 horas de aula por semana", "Metade dos professores não recomenda a profissão aos jovens por causa da desvalorização, diz pesquisa", "A situação do professor brasileiro"7.

Com tal trabalho, temos o intuito de apresentarmos um panorama das condições de produção do ser/estar docente no contexto brasileiro no período de 2014 a 2018, tanto discorrendo sobre a educação e a formação docente quanto desenhando um trajeto que inclui problematização sobre sua (des)valorização, sua identidade, seu papel e função social. O problema que nos inquieta envolve compreender como as condições de produção do magistério no Brasil afetam esta prática social que é a docência.

Nesses artigos, há temas em comum: os autores chamam a atenção para a inflação de tarefas delegadas ao docente, o desconforto em relação ao seu desempoderamento gradual e uma certa degeneração do trabalho de que resulta absenteísmo e, em alguns casos, abandono definitivo da profissão. Mariana Tokarnia, em publicações de 2014 e 2015, chama a atenção para o aumento da desvalorização docente e de situações produtoras de estresse nas escolas. Karina Yamamoto, em artigos de 2014, destaca que, conquanto o professor seja "peça fundamental" em qualquer projeto que envolve investimento e melhoria na/da educação, ele trabalha um número de horas mais elevado que os seus colegas de outros países do mundo e em condições bastante desiguais se forem considerados o número exagerado de alunos por turma e o tempo com planejamento possibilitado pelas instituições. GI Educação (2018) digulgou pesquisa relacionada ao "apagão docente", informando que "Metade dos professores brasileiros não recomenda a própria profissão por considerá-la desvalorizada". Eduardo Freitas (2018), do Canal do Educador/Brasil Escola, sintetiza o que seus colegas apresentaram em seus artigo quando

\footnotetext{
3 Disponível em: http://educacao.uol.com.br/noticias/2014/06/29/quase-90-dos-professores-brasileiros-sesentem-desvalorizados-diz-estudo.htm. Acesso em dezembro de 2018.

4 Disponível em: http://educacao.uol.com.br/noticias/2014/06/25/professor-brasileiro-gasta-20-do-tempo-deaula-com-indisciplina-segundo-estudo-da-ocde.htm. Acesso em dezembro de 2018.

5 Disponível em: http://educacao.uol.com.br/noticias/2014/06/25/em-media-professor-no-brasil-tem-jornadade-25-horas-de-aula-por-semana-ocde.htm. Acesso dezembro de 2018.

6 Disponível em: https://g1.globo.com/educacao/noticia/2018/07/30/metade-dos-professores-nao-recomendaa-profissao-aos-jovens-por-causa-da-desvalorizacao-diz-pesquisa.ghtml._Acesso em dezembro de 2018.

7 Disponível em: https://educador.brasilescola.uol.com.br/trabalho-docente/a-situacao-professorbrasileiro.htm.
} 
adverte que

O professor brasileiro é cercado de um arsenal de burocracias, como: diários, planos de aula, fichas avaliativas, formulários, entre outros. Incluindo ainda a imensa quantidade de trabalho que o professor leva para casa, tais como: plano de aula, elaboração de atividades, provas, trabalhos, correções, testes, projetos etc. Esses não são os únicos agravantes, o professor tem que enfrentar o problema da indisciplina escolar difundida na maioria das escolas brasileiras, como excesso de conversa, bagunça, uso indevido de aparelhos eletrônicos que invadiram as escolas, isso, aliado ao baixo salário, praticado na maioria das vezes. A defasagem salarial não supre todo o trabalho realizado fora da escola, nos finais de semana e feriados.

Sobre tais situações da vida de professor, descritas nos seis artigos selecionados, estudiosos como Gimeno Sácristan, Claude Lessard, Maurice Tardif, Antônio Nóvoa and Dóris Fiss, interessados no currículo e na formação de professores, se manifestam de modo próximo ao dos jornalistas em seus artigos. Por exemplo, Gimeno Sácristan (2000, p. 167) menciona que o docente "[...] não seleciona as condições nas quais realiza seu trabalho e, nessa medida, tampouco pode escolher muitas vezes como desenvolvê-lo”. Ainda segundo Sácristan $(2000 ; 2007)$, mais do que planejador de ações, as funções docentes têm se caracterizado ora pela gestão de problemas que, oriundos de instâncias diversas, são chancelados por estruturas político-administrativas sobre as quais os professores não exercem qualquer influência, ora pela execução de ações que resultam mais de certo treinamento para ministrar disciplinas do que de condições para atender propósitos diferentes da transmissão do conhecimento.

Baseados na discussão acerca dos discursos produzidos sobre o professor nos seis artigos encontrados na internet, no recorte temporal que vai de 2014 a 2018, é tomando o conceito de condições de produção da Análise de Discurso pecheuxtiana que exploraremos o corpus deste trabalho. Esclarecemos que, conquanto o fio condutor de nossos gestos de interpretação envolva a mobilização de uma categoria nuclear à $\mathrm{AD}$, este artigo assume um caráter mais teórico e de contextualização dos aspectos que afetam a profissão-professor no Brasil.

\section{As condições de produção - entre Educação e Análise de Discurso}

Inicialmente, faremos uma breve explanação acerca da Análise de Discurso (AD) 
pecheuxtiana com destaque para o conceito de condições de produção. A AD se constitui como disciplina de entremeio, pois se aproxima dos campos de saberes da linguística, do materialismo histórico e da psicanálise, rompendo com suas fronteiras e engendrando um novo recorte nas ciências. $\mathrm{A} A \mathrm{AD}$ se forma no lugar em que a língua tem que ser referida necessariamente à sua exterioridade atravessada pela história e pelo sujeito, para que se apreenda seu funcionamento enquanto processo significativo. Esta disciplina envolve uma análise contextual das práticas discursivas. Assim, o discurso, que é o objeto de estudo fundamental da AD, é uma criação da lingua(gem) ligado ao seu contexto social, isto é, considera a linguagem em ação, os efeitos engendrados através do seu uso e o sentido social que se constrói, e este sentido se encontra sempre aberto à interpretação.

Dito isto, abordaremos alguns elementos importantes e sem os quais não poderíamos reconhecer os efeitos de sentidos que ecoam nos discursos docentes em uma situação social concreta: as condições de produção (CPs) e o interdiscurso. Eles estão diretamente relacionados à "caixa de conceitos" (FERREIRA, 2005) da AD que inclui: sujeito, língua, discurso, história, ideologia e sentido ${ }^{8}$.

Especificamente no que tange às condições de produção, Courtine (2014) dirá que este conceito se origina de três vertentes: da Análise de Conteúdo que a significa como correspondendo a características circunstanciais de produção de um texto; da Ssociolinguística, com a noção de variáveis, que reconhece a relevância de fatores externos ao texto para sua análise; e de Z. Harris que, em Discourse Analysis, estabelece relação entre discurso e situação (extralinguística). Todas as três "versões" tomam as condições de produção desde uma definição empírica de situação.

Pêcheux (2010) define as CPs, ressignificando o esquema informacional da comunicação criado por Jakobson, que colocava em cena os protagonistas do discurso e seu referente, e permitindo compreender as condições históricas da produção de um discurso dado - o que é dito pelo próprio autor, em Análise Automática do Discurso (AAD69). Pêcheux, ao invés de ver os protagonistas do discurso como "organismos humanos individuais", consegue enxergá-los como representantes de lugares determinados em uma

8 Tais conceitos não serão aprofundados em virtude de este trabalho não pretender a realização de uma análise de discurso propriamente dita, mas assumir um caráter mais teórico e de contextualização dos aspectos que afetam a profissão-professor no Brasil. 
estrutura social, dos quais derivam diferentes formações imaginárias.

Porém, o conceito de CPs da AD pecheuxtiana recebeu crítica de Courtine, pois, segundo este, Pêcheux não explorou concretamente a exterioridade dos enunciados em suas CPs, deixando de lado as contingências dos próprios acontecimentos que intervêm na estabilidade do "já-lá". Tal ponto de vista assumido por Pêcheux acarretou numa compreensão que aponta para uma homogeneidade discursiva, para o fechamento da Formação Discursiva (FD) que é compreendida como homogênea. Dito de outra forma, Courtine (2014, p. 51) propõe que se considerem as contradições ideológicas manifestas na materialidade dos discursos desde sua articulação com as FDs:

[...] a noção de CP do discurso apresenta um conteúdo ao mesmo tempo empírico e heterogêneo. [...]. Na verdade, tanto no quadro da definição geral proposta por Pêcheux (1969) quanto na realização da noção como hipótese específica em uma pesquisa particular, ficou evidente que na ausência de uma hierarquização teórica dos planos de referência da noção, o plano psicossociológico (que estabelece como quadro a situação de enunciação, as interações verbais dos locutores nessa situação e as hipóteses tipológicas que estão ligadas a ela) domina, de fato, o plano histórico de caracterização das CP.

A esse respeito, Zandwais (2009, p. 56) considera importante

[...] o fato de que é justamente em virtude de uma leitura mais comprometida com os domínios da práxis [...] que Jean Jacques Courtine consegue repensar quais seriam alguns dos objetos reais da $\mathrm{AD}$, se pensada como uma disciplina que precisa focalizar, sobretudo, seu olhar sobre as práticas sociais e as formas de discursividades que lhes correspondem em suas contradições.

As CPs abrangem os sujeitos e o contexto, isto é, a situação do dizer, mas não podem ser reduzidas às circunstâncias empíricas como proposto pela Análise de Conteúdo, pela Sociolinguística e por Harris respectivamente. Este contexto foi compreendido por Orlandi (2012), em seu sentido estrito, como imediato e, em seu sentido lato, como amplo. O contexto amplo inclui o contexto sócio-histórico e ideológico, remetendo, na consideração dos efeitos de sentidos, a elementos derivados da forma da sociedade e da história. O contexto imediato é o próprio momento do dizer, ou seja, as circunstâncias da enunciação.

As CPs também incluem a memória que as ativa, as torna válidas. Ela é tratada como interdiscurso, ou seja, aquilo que fala antes, em outro lugar, de maneira independente, 
autorizando-nos a remeter o enunciado a toda uma filiação de enunciados, a uma memória, e a identificá-lo em sua historicidade, revelando seus compromissos sociais, políticos e ideológicos. Pêcheux (1999, p. 52) chama também o interdiscurso de memória discursiva que, conforme ele,

Seria aquilo que, face a um texto que surge como acontecimento a ler, vem restabelecer os "implícitos" (quer dizer, mais tecnicamente, os pré-construídos, elementos citados e relatados, discursos-transversos, etc.) de que sua leitura necessita: a condição do legível em relação ao próprio legível.

Já Courtine (2014, p. 74) vai dizer que o interdiscurso é

[...] o lugar no qual se constituem, para um sujeito falante, produzindo uma sequência discursiva dominada por uma FD determinada, os objetos de que esse sujeito enunciador se apropria para deles fazer objetos de seu discurso, assim como as articulações entre esses objetos, pelos quais o sujeito enunciador vai dar uma coerência à sua declaração, no que chamaremos o intradiscurso da sequência discursiva que ele enuncia.

Diante disso, podemos entender que a memória discursiva, ou interdiscurso, transforma todo o conhecimento/saber discursivo em uma prática discursiva, retomado sob a figura do pré-construído, do já-dito que fica no apoio do que se diz, usando como alicerce cada palavra.

Para Pêcheux (2009), o interdiscurso oferece enunciados que influenciam diretamente na maneira como o sujeito vai significar em uma situação de discurso determinada. O fato de que todo o dizer é alicerçado por um já-dito, um já-lá, é de grande relevância para se entender a função do discurso, a sua relação com os sujeitos e com a ideologia.

Tomando tais acepções, procuramos entender como a prática docente no Brasil, através da consideração das condições de produção da profissão-professor, se faz e refaz em sua historicidade. Destacamos que a relação entre as palavras de um texto, como os artigos que constituem o corpus considerado, e seus sentidos não é natural, estável e unívoca - o que se ratifica ao lembrarmos que pensar o discurso em sua especificidade implica abordar a relação que se estabelece entre o linguístico e o ideológico, estando aí presentes relações contraditórias como as constituídas, quando se considera a prática docente. Relações entre tensões e rupturas, entre o ser e o não-ser, entre o gosto e o 
desgosto pela docência, entre a satisfação e a insatisfação, entre o fascínio e a desilusão, pondo o sujeito em uma relação dialética com sua profissão.

Nos artigos aqui considerados, tais relações contraditórias são confirmadas pela constante referência à tensão entre contextos que impõem dificuldades e aflições aos professores e a permanência deles no magistério por compromisso, paixão, desejo de transformação social. Em publicação de 2014, Tokarnia adverte que: "Quase 90\% dos professores brasileiros acreditam que a profissão não é valorizada na sociedade. Mesmo assim, a maioria está satisfeita com o emprego", combinando sentidos antagônicos desvalorização e satisfação - que se movimentam de modo contraditório nos depoimentos analisados pela pesquisadora. Um ano depois, Tokarnia (2015), em outro artigo, permite reiterar o contraditório quando refere, ao mesmo tempo, a história de 30 anos de dedicação ao magistério de certa docente e a debilidade física que enfrenta por problemas de saúde derivados do mundo do trabalho sem que a profissional se desse conta disso: "Com 49 anos e 30 de profissão, Avelina pediu aposentadoria para o início do ano que vem. As lágrimas, segundo ela, são menos por deixar a escola e mais por avaliar o que o exercício do magistério lhe causou. A lista de enfermidades inclui problemas gástricos, irritabilidade, problemas nas articulações".

A docência é uma carreira profissional afetada por situações que se agravam em virtude de: baixos salários ou a falta de pagamento deles, descredibilidade por algumas instituições sociais, falta de perspectiva de um projeto futuro na carreira do professor, crise nas organizações escolares e a função, hoje, tortuosa da docência, tendo por base a crise social e a nova forma de tratar o ensino - como massa ${ }^{9}$. Por tais fatores, esta profissão torna-se extremamente complexa, consequentemente, dificultando sua estrutura e o modo de funcionar, como pontuam Tardif e Lessard (2014, p. 9) quando mencionam que "[...] o ensino se tornou um trabalho especializado e complexo, uma atividade rigorosa que exige daqueles e daquelas que exercem a existência de um verdadeiro profissionalismo".

Nóvoa (1995) teoriza que a profissão docente é influenciada por dois processos antagônicos, existindo sob forte tensão: profissionalização e proletarização. No que se

9 É a transformação das escolas tradicionais em escolas de massa, que, em tese, significa uma abertura para todos sob a responsabilidade do Estado. (TARDIF; LESSARD, 2014, p. 9). 
refere a esta, existe uma enorme tendência de intensificar o trabalho docente com inflação de atividades diárias e uma sobrecarga permanente de tarefas escolares e não-escolares. Já no que tange à profissionalização, o docente sofre com a legitimidade da profissão, pois a elaboração dos currículos e dos programas da sua concretização pedagógica é feita por especialistas científicos e destaca as características técnicas do trabalho do educador, provocando uma degradação do seu status e retirando-lhe a sua autonomia profissional.

Enfim, o que vivenciamos, na vida como professor, é uma incompatibilidade ou mesmo uma controvérsia entre os estudos, a teoria, a lei e a realidade do docente. $\mathrm{O}$ modo como este tem sido tratado pelo governo, pela instituição escolar, pela instituição família é indigno, preocupante, humilhante e, até mesmo, desumano, não evidenciando respeito pelos seus saberes ou pelas funções que desempenha nos espaços escolares e não-escolares. Conforme afirma Aquino (2003, p. 378), "Indisciplina, agressividade, revanchismo e apatia são alguns sintomas levantados pelos educadores; todos eles, ao que parece, decorrências de pouca credibilidade institucional auferida pelas agências escolares entre sua clientela e público mais imediato, as famílias”.

Se consideradas as condições de produção como o momento imediato de irrompimento dos discursos docentes e sobre a docência, constatamos, a partir dos artigos, que os tempos do professor brasileiro apontam para políticas públicas que não priorizam a educação nem investem na valorização financeira ou profissional do mesmo, o que reverbera, se tomadas as CPs num sentido mais amplo, em uma memória da educação que, abrigada sob a influência da ideologia capitalista, deixa escapar um sentido de trabalho docente como ofício que envolve heroísmo - mesmo que esgotado pela inflação de tarefas e a desvalorização, o docente realiza o que se espera dele por ser esta a missão a que está destinado. Termos como "peça fundamental", "satisfação", “enfermidades" e "estresse”, repetidos nos seis artigos lidos, permitem especular como a ideologia funciona naturalizando a proletarização do docente ao mesmo tempo em que parece conferir algum tipo de reconhecimento ao professor - ele continua sendo chamado de "peça fundamental" sem ser tratado como agente de fato importante.

Depreende-se daí que a identidade do professor passa por um complexo e difícil processo de representação social e profissional, que envolve a procura, por parte dos 
próprios docentes em seu fazer diário, pela desmistificação do pensamento arcaico segundo o qual o ofício do magistério precisa somente de um conhecimento específico somado à "pré-disposição para ser dar bem com crianças". Nóvoa (2014, p. 227), sobre tema tão delicado, assim se posiciona: “[...] os professores nunca viram o seu saber específico devidamente reconhecido. Mesmo que se reitere a importância de sua missão, a tendência é considerar sempre que lhe basta dominar bem a sua matéria de ensino e ter aptidão para a comunicação, para o trabalho com os alunos”. O docente sabe (e aprende na prática) que, para ensinar, necessita mais do que conhecimento específico. A docência exige conhecimentos, competências e habilidades do professor que vão além do saber científico, é necessário conhecer a realidade do seu alunado mais de perto. Nesse prisma, Tardif e Lessard (2014, p. 9) afirmam que, para ser professor, o sujeito precisa das

[...] aptidões e das atitudes próprias para facilitar a aprendizagem dos alunos: respeito aos alunos; habilidades de comunicação; capacidade de empatia; espírito de abertura às diferentes culturas e minorias; habilidade para colaborar com os pais e outros atores etc.; assim como uma boa dose de autonomia e o exercício de um julgamento profissional respeitoso tanto das necessidades dos alunos quanto das exigências da vida escolar e social.

Diante dessas condições de produção do ofício do professor, no que concerne à situação enfrentada por ele no Brasil, os docentes se caracterizam pela indefinição no que se refere à sua imagem profissional, isto é, à sua identidade docente. As exigências e responsabilidades da prática docente, junto com o tempo e os recursos disponíveis, colaboram para um crescente mal-estar docente e para uma ansiedade difícil de suportar, influenciando, assim, no ambiente de trabalho, no status social e na imagem do professor.

Dito isto, um fator que chama atenção, e que corrobora com as incertezas do ser professor, é o despreparo que muitos educadores relatam acerca de sua formação prática. Eles revelam não ter formação didática adequada para o trabalho com os diversos conteúdos das áreas de conhecimento específicas - o que surge, no artigo de Yamamoto (2014a) quando ela enuncia que:

Cerca de metade dos professores brasileiros não têm formação didática para todas as matérias que ensinam. Por exemplo, o professor de história não aprendeu como ensinar esse conteúdo aos alunos do ensino fundamental 2 , que vai do $6^{\circ}$ ao $9^{\mathrm{o}}$ anos (chamado anteriormente de $5^{\mathrm{a}}$ a $8^{\mathrm{a}}$ série) ou o responsável por matemática 
não aprendeu métodos e técnicas para passar o conteúdo da sua disciplina. [...] Quatro em cada dez professores brasileiros não tiveram formação para a prática de sala de aula para todas as matérias que ensinam durante a faculdade. Isso significa que eles não aprenderam a lidar com problemas de indisciplina ou como trabalhar com adolescentes, por exemplo.

Junto a isto, relaciona-se, também, o chamado mito da incompetência sustentado pelo modo como o professor tem sido compreendido quanto ao seu papel e às suas funções, como afirma Fiss (2003, p. 164)

\begin{abstract}
O sistema escolar, primeiro, admite a competência dos professores, tanto que lhes possibilita o estabelecimento de um vínculo de trabalho e coloca-os na posição de trabalhadores da educação aptos a exercer as funções atinentes a tal papel. Pouco depois, ataca esses profissionais de formas variadas que questionam a referida competência. Seria dizer que, a partir de um certo momento difícil de precisar, deixa de tratá-los como profissionais: exige cursos, impõe uma relação de emprego em que os direitos do trabalhador não são respeitados, submete-os a condições de trabalho que não oportunizam, muitas vezes, a possibilidade de continuar estudando.
\end{abstract}

Percebe-se, pois, que o chão da escola tem sido palco de embates diversos que tocam os docentes em suas relações com o trabalho. Soma-se a isso o fato de que o sucateamento das escolas públicas pelas alterações constantes nos processos produtivos torna o trabalho duro, penoso, fragmentado e insuscetível de ser motivo de autoestima para significativas camadas de trabalhadores. Destarte, a identidade docente continua marcada pela indefinição no que concerne ao que é ser professor, resultando disso a manutenção da apreensão e do mal-estar.

Outro aspecto a ser pontuado, no campo das identidades docentes, diz respeito à consideração das práticas docentes como constitutivas das mesmas e à relevância do conhecimento individual do professor. Dito de outra forma, o educador vai buscar sua experiência escolar em tempos que remontam aos seus estudos infantis e se estendem até os acadêmicos, correspondendo à maneira como ele constrói a forma de ser professor durante os anos de sua vida, num processo de ensino-aprendizagem iniciado em seus dias de estudante em tenra idade. Tardif (2012, p. 20) ratifica tais afirmações, dizendo que

O saber do professor é plural e também temporal [...] é adquirido no contexto de uma história de vida e de uma carreira profissional [...]. Dizer que o saber dos professores é temporal significa dizer, inicialmente, que ensinar supõe aprender a 
ensinar, ou seja, aprender a dominar progressivamente os saberes necessários à realização do trabalho docente.

O autor destaca que essa temporalidade envolve a história escolar e familiar dos professores e a carreira profissional. Ao remeter ao saber adquirido "[...] no contexto de uma história de vida e de uma carreira profissional", a temporalidade pode ser associada a uma espécie de legado: o docente herda modos de pensar a educação que remontam à sua experiência escolar como aluno e, do mesmo modo, se atualiza quanto aos seus modos de ser e fazer(-se) em função das condições em que se dá sua ação e da natureza relacional da mesma. Em função disso, o autor canadense insiste na importância de compreender a experiência de trabalho como fundamento do saber, valorizando o professor e seus modos de ser na escola. Seguindo este pensamento, Nóvoa (1995, p. 25) menciona que

\begin{abstract}
A formação não se constrói por acumulação (de cursos, de conhecimentos ou de técnicas), mas sim através de um trabalho de reflexividade crítica sobre as práticas e de (re)construção permanente de uma identidade pessoal. Por isso é tão importante investir na pessoa e dar um estatuto ao saber da experiência.
\end{abstract}

Por muito tempo, os cursos de formação de professores priorizavam as teorias e as técnicas científicas, deixando a prática em segundo plano, não dando atenção especial à prática de ensino concreta e efetiva que se faz no chão da escola. Hoje, o maior problema na formação docente é a fronteira que existe entre a teoria e a prática, desafiando os especialistas a articular o sucesso do saber com o saber-fazer.

Para Lima (2017), o profissional docente, que está iniciando, tem muita insegurança nascida dos temores gerados pela prática. Esta é uma preocupação que se eleva quando a formação acadêmica não dá suporte suficiente ao exercício da profissão por nem sempre considerar que é com a prática do cotidiano que o professor aprenderá o saber-ser e o saberfazer, ou seja, o educador vai forjar sua identidade e seus saberes profissionais a partir de sua prática do dia a dia, tendo a teoria como suporte. Consoante ressalva Tardif (2012) e Tardif e Lessard (2014), as identidades docentes se constituem afetadas por uma rede de saberes na qual todos são igualmente importantes.

Nóvoa (1995) acrescenta argumentos outros ao debate sobre a formação docente. Ele se utiliza de dois pontos: o primeiro, pensar a formação do professor a partir de uma 
reflexão fundamental a respeito da própria formação; e o segundo, relacionar esta formação com o desenvolvimento pessoal, profissional e organizacional, ou seja, é necessário olhar para o professor como um todo desde sua vida pessoal, passando pela profissional, que envolve seu trabalho do cotidiano e, por fim, sua relação com a escola.

Pode-se concluir que os docentes mobilizam saberes próprios ao seu ofício e, como sujeitos de conhecimento, não se limitam a ser executores de tarefas ou reprodutores de saberes pensados e propostos por outros. Diante disso, é impossível as instituições responsáveis pela formação profissional não questionarem uma tal realidade pela problematização dos modos como licenciandos, em formação inicial, ou professores, em formação continuada, são desafiados (ou não) a lidar com problemas no campo científico e fragilidades nos currículos de cursos que ainda permanecem distantes de uma compreensão não dicotômica de teoria e prática docente, de uma compreensão que reconheça a escola como lugar privilegiado de constituição de saberes tão relevantes quanto aqueles que se movimentam na academia.

Dessa forma, assumindo posicionamento para além das bases tradicionais (componente científico $\mathrm{x}$ componente pedagógico; disciplinas teóricas $\mathrm{x}$ disciplinas metodológicas, etc), destacamos a importância e necessidade da proposição de novas formas de pensar as dificuldades que a formação para o exercício do magistério encontra hoje, sempre numa corrente de (trans)formação contínua, ou seja, num processo de reconhecimento cada vez maior do ser sujeito-docente, de suas histórias, de seus saberes, de suas lutas.

A Lei de Diretrizes e Bases da Educação Nacional (LDBEN), nos artigos 61 a 67, discorre acerca de: fundamentos da formação dos profissionais da educação; níveis de formação docente exigidos à atuação dos professores na educação básica; competências dos Institutos Superiores de Educação (ISE); tempo mínimo à prática de ensino na formação dos docentes da educação básica; e estratégias para valorização dos profissionais da educação (estatuto, planos de carreira, condições de trabalho). Mas nada disto será útil se os direitos estabelecidos em tal documento legal não forem cumpridos, assegurando uma melhor qualidade de vida profissional e um aumento significativo no desenvolvimento da educação no Brasil. Teremos educadores que perdem o desejo da docência. E teremos um 
país que perde, nas mais diversas áreas, por não fazer que se cumpram as leis que "garantem" uma educação nacional de qualidade.

Mesmo pressupondo que tais direitos possam ser efetivamente realizados, é necessário que sejam promovidas políticas públicas de educação comprometidas com atividades que envolvam interação entre os agentes da comunidade escolar - pais, responsáveis, educandos, e os agentes da formação dos educandos - professores. A comunidade da escola precisa voltar a confiar no professor e acreditar em suas práticas de ensino, a fim de que os problemas relacionados ao mal-estar docente e à diminuição de sua credibilidade diante da sociedade, muitas vezes diante da própria comunidade, e o chamado fracasso escolar sejam amenizados ou, num pensamento mais otimista, erradicados.

O ensino não pode ser visto como uma tarefa simples e fácil que os docentes já nascem sabendo realizar, sem necessidade, portanto, de capacitação, qualificação e experiência. Sobre a complexidade do ensino, Nóvoa (2014, p. 229) expõe três ideias: "[...] ao contrário de outros profissionais, o trabalho docente depende da 'colaboração' do aluno $[\ldots] ”$, “.... a atividade docente se caracteriza também por uma grande complexidade do ponto de vista emocional. Os docentes vivem num espaço carregado de afetos, de sentimentos e de conflitos [...]" e "[...] pedimos à educação que cumpra objetivos distintos, às vezes contraditórios: desenvolver a pessoa e formar o trabalhador, garantir a igualdade de oportunidades e a seleção das elites, promover a mobilidade profissional e a coesão social".

O contexto nacional de produção da docência revela que há situações do dia a dia docente que comportam exigências maiores e mais complexas do que aquelas demandadas de outras profissões. Estamos falando sobre organização das atividades extracurriculares, preparação das aulas, participação nas reuniões pedagógicas, envolvimento nos problemas da administração da escola, relação afetiva com o educando e, às vezes, conflitos familiares dos alunos. Yamamoto, em artigo publicado em 2014c, lembra que: “Os professores brasileiros gastam, em média, 20\% do tempo de aula mantendo a disciplina na classe, segundo levantamento internacional. Ou seja, o docente gasta um em cada cinco minutos pedindo silêncio ou chamando a atenção por bagunça”.

Diante da realidade atual, percebemos que a Lei não condiz com a situação 
cotidiana dos docentes. Uma pesquisa realizada em 2013, elaborada pela Talis ${ }^{10}$ e coordenada pela OCDE (Organização para Cooperação e Desenvolvimento Econômico), divulgada em site brasileiro, reforça esta contradição. Ela aponta que, dentre inúmeras dificuldades que atingem a área da educação, duas se mostram bem evidentes e, de certa maneira, estão imbricadas: a valorização do docente e a qualidade do ensino.

Os dados apresentados na pesquisa revelaram que o professor brasileiro trabalha mais que os de outros países: aquele tem, em média, uma carga horária de 25 (vinte) horas semanais, o que equivale a 6 (seis) horas a mais que a média destes. Mas, infelizmente, a dificuldade não para somente aí: além do número de horas a mais, o docente brasileiro enfrenta o grande desafio de uma sala de aula lotada. ${ }^{11}$. Dentro do planejamento, devem constar o delineamento do plano de aula, a correção de trabalhos e provas, reuniões com pais, colegas professores e equipe diretiva. Isto é, o professor do Brasil possui uma carga horária excessiva com um planejamento que nem sempre corresponde às necessidades que surgem durante o processo de trabalho.

Com o inchaço da sala de aula, aumentando o número de alunos vertiginosamente, o pouco ou nenhum interesse em aprender demonstrado pelos mesmos e a indisciplina, problemas de saúde têm acometido o docente. Como dito parágrafos antes, ao se aposentar, ele/a acumula patologias originadas pela profissão a que tanto se dedicou. De acordo com o estudo efetivado, publicado em 2014, pelo Conselho Nacional de Secretários de Estado da Administração (Consad) sobre as relações entre doença e trabalho consideradas a partir de respostas obtidas em três estados - Espírito Santo, Rio Grande do Sul, Santa Catarina - e no Distrito Federal (DF), a Secretaria de Educação se configura como o órgão com maior percentual de servidores públicos afastados por doenças no DF (58\% solicitaram afastamento por problemas médicos) e em Santa Catarina (25\% dos profissionais precisaram se afastar em algum momento). No Rio Grande do Sul, a educação surge como

10 Talis é a sigla para Pesquisa Internacional sobre Ensino e Aprendizagem (Teaching and Learning International Survey em inglês), coordenada pela OCDE (Organização para Cooperação e Desenvolvimento Econômico). No Brasil, a coordenação da pesquisa fica por conta do Inep (Instituto Nacional de Estudos e Pesquisas Educacionais Anísio Teixeira).

11 Segundo consta no texto consultado, 34 países e territórios (24 da OCDE e outros 10 parceiros, como o Brasil) fizeram parte da pesquisa. Aproximadamente 106 mil professores responderam à pesquisa. No Brasil, foram consultados 14.291 professores dos anos finais do ensino fundamental e 1.057 diretores de 1.070 escolas. 
a área com o terceiro maior índice de afastamento entre as secretarias do estado, $30 \%$.

$\mathrm{Na}$ investigação "Trabalho Docente na Educação Básica no Brasil”, publicada em revista da Confederação Nacional dos Trabalhadores da Educação (CNTE), são enumeradas as principais causas de afastamento dos educadores: processos inflamatórios das vias respiratórias $(17,4 \%)$, depressão, ansiedade, nervosismo, síndrome do pânico $(14,3 \%)$ e estresse $(11,7 \%)$. Foram consideradas respostas dadas por 8,9 mil professores que atuam em escolas de Minas Gerais, Espírito Santo, Goiás, Paraná, Santa Catarina, Rio Grande do Norte e Pará. Com esta pressão que a profissão docente sofre, o professor tem sido forçado a se adaptar, muitas vezes, não conseguindo lidar com as condições resultantes das intempéries que o ofício exige que sejam enfrentadas nem acompanhando o ritmo imposto por tais situações.

\section{Considerações finais}

Ao pensar o discurso, a AD possibilita a análise dos efeitos de sentidos entre locutores, vinculando a linguagem ao seu contexto. Ao propor a articulação entre Educação e $\mathrm{AD}$, mesmo que a partir de apenas um dos seus conceitos - as condições de produção, cabe ao pesquisador um trabalho que possibilite compreender a relação entre a ordem da língua (ordem significante que funciona pelo imaginário) e a ordem da história vinculada às formações sociais que são sensíveis às regras de projeção que estabelecem relação entre situações (objetivamente definíveis) e as posições dos sujeitos (representações dessas situações). Considerando que este artigo buscou descrever as condições de produção da docência no Brasil pela consideração de dados extraídos de seis artigos disponíveis na mídia virtual e de estudos realizados por pesquisadores comprometidos com a formação de professores, a $\mathrm{AD}$, tanto em sua dimensão teórica quanto operatória, se coloca como parceira na reflexão sobre este contexto discursivo que é a educação, demandando, na continuidade do trabalho, um reinvestimento no material explorado aqui desde uma perspectiva mais próxima do campo discursivo propriamente dito.

Nesse sentido, CP é um conceito nuclear da AD que possui a característica básica de abranger o contexto histórico e a memória discursiva. Ou seja, as CPs envolvem o sujeito, 
sua situação e a memória discursiva, passando por isso as formações imaginárias constituídas pelos sujeitos do discurso. O discurso é caracterizado e configurado como objeto da AD por meio das CP, uma vez que o interesse da AD se concentra no modo de funcionamento da linguagem. No que tange a isso, Lima (2017, p. 93) vai dizer que as condições de produção docente

[...] permitem identificar uma tensão entre a teoria e a prática que vem acompanhada de certo medo manifesto pelo educador de enfrentar a realidade da sala de aula. Em sua prática docente, ele se depara com dificuldades de abordar teorias, às vezes ultrapassadas, num contexto atual, onde a diversidade cultural, étnica, social é tão evidente nas instituições públicas. Especializações/Formações ocorrem, mas diante de um público que se torna cada vez mais complexo e o qual nem sempre os agentes formadores conseguem compreender. A identidade docente que está sempre a se constituir no ser/estar professor/a a partir de desafios novos. Enfim, as temáticas que tomam o/a professor/a como foco mostram as tensões que ele/a vive no sua jornada docente.

O primeiro movimento, aqui apresentado, de mobilização deste conceito para delinear as condições de produção do magistério em nosso país permite reiterar tanto a potência do trabalho com a $\mathrm{AD}$ quanto descobertas preliminares que apontam para a memória da educação, ao mesmo tempo, estabilizada e atualizada desde sentidos que se associam, por um lado, à valorização cultural, financeira, de formação do professor, ao bem-estar docente, e, por outro lado, às dificuldades com que o professor se depara na sua vida docente: a diversidade social e cultural dos alunos dentro de sala de aula, a indisciplina e falta de respeito, a desvalorização salarial, as condições precárias da escola, o abandono da educação pelos governos, os problemas de saúde em virtude de uma sala lotada, de excessivas burocracias. A nuvem de palavras produzida ratifica tal conclusão na medida em que permite reconhecer as palavras que foram ditas demais nos seis artigos abordados no desenho das condições de produção da docência em nosso país:

Figura 1 - Condições de produção do docência em nuvem 


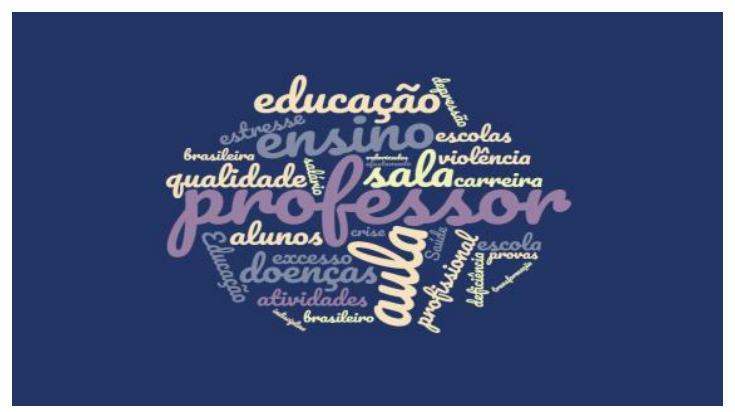

Fonte: material elaborado pelo autor a partir de https://www.wordclouds.com/

Ainda que professor seja a palavra mais dita, ela vem margeada por ensino, que é possível articular com aula, educação, carreira, alunos, atividades, provas, sala, escolas, e doenças, que se pode relacionar com estresse, saúde, depressão, afastamento, crise, violência, excesso, deficiência. Dadas as condições de produção da docência no nosso país, ser enunciado como "peça fundamental" do processo de educação parece insuficiente no que se refere à perturbação de redes de sentidos nas quais habitam tensões entre o sentido de valorização docente pela real importância de seu trabalho e o sentido de proletarização docente pela desconsideração desse trabalhador de que deriva seu adoecimento. No dito “professor”, ecoam não-ditos que, resultando de modos difíceis de ser/estar docente cujos sentidos ressoam da desvalorização e do mal-estar, se estilhaçam em sentidos de docência como algo menor, secundarizado. Nesse dito "professor", são surpreendidos já-lá que, (re)constituindo a memória da educação no Brasil, insistem em enunciá-la num contexto de embate tenso entre decisões favoráveis ao educador, como as expressas na Constituição Federal, na LDBEN e no PNE, e outras menos favoráveis, como as vividas em uma escola com turmas numerosas, horas de planejamento limitadas e riscos de adoecimento. A ideologia funciona de modo a tornar estas circunstâncias óbvias, evidentes. A ideologia funciona de modo a que as condições de produção da docência não causem estranhamento ou indignação. E a Análise de Discurso, aliada à Educação, permite que a suspeita se constitua em função da necessária consideração da relação entre língua(gem) e exterioridade de que deriva possibilidades outras de interpretar e resistir ao sentido dado, ao estabilizado, ao tomado como evidente. 


\section{REFERÊNCIAS}

AQUINO, Julio G. Disciplina e indisciplina como representações na educação contemporânea. In.: BARBOSA, Raquel Lazzari L. (org.). Formação de educadores: desafios e perspectivas. São Paulo: Editora UNESP, 2003. p. 377-386.

BRASIL [Constituição (1988)]. Constituição da República Federativa do Brasil [recurso eletrônico] : texto constitucional promulgado em 5 de outubro de 1988, com as alterações adotadas pelas Emendas constitucionais n. 1/1992 a 90/2015, pelo Decreto legislativo $\mathrm{n}^{\circ}$ 186/2008 e pelas Emendas constitucionais de revisão no ${ }^{\circ} 1$ a 6/1994. - 48. ed. - Brasília : Câmara dos Deputados, Edições Câmara, 2015. - (Série textos básicos ; n. 119). Disponível em: http://www2.camara.leg.br/documentos-e-pesquisa/publicacoes/edicoes/paginasindividuais-dos-livros/constituicao-da-republica-federativa-do-brasil-2. Acesso em:

BRASIL, Ministério da Educação e do Desporto, Secretaria de Educação Fundamental. Parâmetros curriculares nacionais. Brasília: MEC/SEF, 1998.

COURTINE, Jean-Jacques. O conceito de formação discursiva. In: COURTINE, JeanJacques. Análise do discurso político: o discurso comunista endereçado aos cristãos. São Paulo: EduFSCar, 2014. p. 69-96.

FERREIRA, Maria Cristina Leandro. O quadro atual da Análise de Discurso no Brasil. In: INDURSKY, Freda; FERREIRA, Maria Cristina Leandro. Michel Pêcheux e a Análise de Discurso: uma relação de não se acabar. São Carlos: Claraluz, 2005. p. 13-22.

FISS, Dóris M. L. Os processos de construção da autoria e do mal-estar docente numa escola pública estadual. Porto Alegre: Universidade Federal do Rio Grande do Sul, 1998. Faculdade de Educação, Programa de Pós-Graduação em Educação. Dissertação (Mestrado). $228 \mathrm{f}$.

. Territórios incertos: os processos de subjetivação das professoras da rede pública estadual. Porto Alegre: Universidade Federal do Rio Grande do Sul, 2003. Faculdade de Educação, Programa de Pós-Graduação em Educação. Tese (Doutorado). 288 f.

FREITAS, Eduardo. A situação do professor brasileiro. Disponível em: https://educador.brasilescola.uol.com.br/trabalho-docente/a-situacao-professor- 
brasileiro.htm. Acesso em dezembro de 2018.

GI EDUCAÇÃO. Metade dos professores não recomenda a profissão aos jovens por causa da desvalorização, diz pesquisa. Disponível em: https://g1.globo.com/educacao/noticia/2018/07/30/metade-dos-professores-nao-recomendaa-profissao-aos-jovens-por-causa-da-desvalorizacao-diz-pesquisa.ghtml. Acesso em dezembro de 2018.

LIMA, Marcos S. S. Discurso e docência: efeitos de sentidos da permanência docente em uma escola pública. Porto Alegre: Universidade Federal do Rio Grande do Sul, 2017. Faculdade de Educação, Programa de Pós-Graduação em Educação. Dissertação (Mestrado). $109 \mathrm{f}$.

NÓVOA, António. Formação de professores e profissão docente. In: (org.). $O s$ professores e sua formação. 2. ed. Lisboa: Dom Quixote, 1995. p.13-33. . Os professores e o "novo" espaço público da educação. In.: TARDIF, Maurice; LESSARD, Claude (orgs.). O ofício de professor: história, perspectivas e desafios internacionais. 6. ed.. Petropolis, RJ; Vozes, 2014. p. 217-233.

ORLANDI, Eni P. Análise de Discurso: princípios e procedimentos. 10. ed. Campinas, SP: Pontes Editores, 2012.

PÊCHEUX, Michel. Análise Automática do Discurso (AAD69). In: GADET, Françoise; HAK, Tony (orgs.). Por uma análise automática do discurso: uma introdução à obra de Michel Pêcheux. 4. ed. Campinas, SP: Editora da UNICAMP, 2010.

. Papel da memória. In: ACHARD, Pierre et al. Papel da Memória. Tradução e introdução José Horta Nunes. Campinas, SP: Pontes, 1999. p. 49-57.

. Semântica e discurso: uma crítica à afirmação do óbvio. Tradução Eni Pulcinelli Orlandi (et al). 4. ed. Campinas, SP: Editora da UNICAMP, 2009.

SACRISTÁN, J. Gimeno. O currículo modelado pelos professores. In: $O$ currículo: uma reflexão sobre a prática. 2. ed. Porto Alegre: Artmed, 2000. p. 165-199. . O que são os conteúdos de ensino? In: SACRISTÁN, J. Gimeno; GÓMEZ, A.I. Pérez. Compreender e transformar o ensino. Porto Alegre: Artmed, 2007. p. 149-195. TARDIF, Maurice. Saberes docentes e formação profissional. 14. ed. Petrópolis, RJ: 
Vozes, 2012.

TARDIF, Maurice; LESSARD, Claude (orgs.). Trad. De Lucy Magalhães. O ofício de professor: história, perspectivas e desafios internacionais. 6. ed. Petropolis, RJ; Vozes, 2014.

TOKARNIA, Marina. Professor sofre com estresse, violência e falta de tempo para planejar aula. $\quad$ http://educacao.uol.com.br/noticias/2015/10/15/professor-sofre-com-estresseviolencia-e-falta-de-tempo-para-planejar-aula.htm. Acesso em dezembro de 2018.

. Quase 90\% dos professores brasileiros se sentem desvalorizados, diz estudo. Disponível em: http://educacao.uol.com.br/noticias/2014/06/29/quase-90-dos-professoresbrasileiros-se-sentem-desvalorizados-diz-estudo.htm. Acesso em dezembro de 2018.

ZANDWAIS, Ana. Perspectivas da análise do discurso fundada por Michel Pêcheux na França: uma retomada de percurso. Santa Maria: Universidade Federal de Santa Maria, Programa de Pós-Graduação em Letras, 2009.

YAMAMOTO, Karina. Brasil. 50\% dos professores não têm didática para tudo que ensinam. Disponível em: http://educacao.uol.com.br/noticias/2014/06/25/brasil-50-dosprofessores-nao-tem-didatica-para-tudo-que-ensinam.htm. Acesso em: 16 dez. 2018.

YAMAMOTO, Karina. Em média, professor no Brasil tem jornada de 25 horas de aula por semana. Disponível em: http://educacao.uol.com.br/noticias/2014/06/25/em-mediaprofessor-no-brasil-tem-jornada-de-25-horas-de-aula-por-semana-ocde.htm. Acesso dezembro de 2018.

YAMAMOTO, Karia. Professsor brasileiro gasta $20 \%$ do tempo de aula com indisciplina. Disponível em: http://educacao.uol.com.br/noticias/2014/06/25/professor-brasileiro-gasta20-do-tempo-de-aula-com-indisciplina-segundo-estudo-da-ocde.htm. Acesso em dezembro de 2018. 